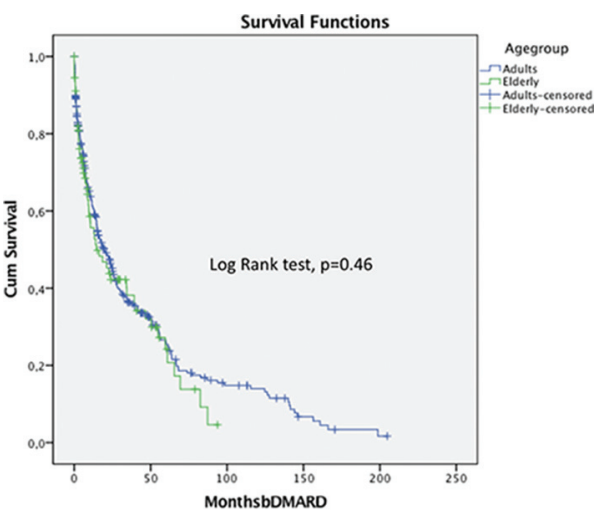

Figure 1 - Persistence in 1"s bDMARD (months) for elderly and adults

\begin{tabular}{|c|c|c|c|c|}
\hline Efficacy and safety & Total & Adults & Eldery & Pvalue \\
\hline EULAR response at 3 month (Lundex corrected) \% & $77.8(51)$ & $78.4(51)$ & $75(51)$ & \\
\hline EULAR response at 6 month (Lundex corrected) \% & $80.6(50)$ & $81.7(52)$ & $76(45.2)$ & \\
\hline EULAR response at 12 month (Lundex corrected) \% & $81.5(35.6)$ & $83.8(37)$ & $71.5(29.3)$ & 0,01 \\
\hline N patients with AE during 1st bDMAR & 409 & 319 & 90 & \\
\hline AE infection $-\mathrm{N}(\%) \mathrm{N}=407$ & $237(58,2)$ & $176(55,3)$ & $61(68,5)$ & 0,03 \\
\hline AE opportunist infection $-\mathrm{N}(\%) \mathrm{N}=408$ & $30(7,4)$ & $21(6,6)$ & $9(10)$ & \\
\hline AE allergic reaction $-N(\%) N=407$ & $71(17,4)$ & $59(18,6)$ & $12(13,5)$ & \\
\hline Severe AEs- $N(\%) N=391$ & $82(21)$ & $64(21)$ & $18(20,9)$ & \\
\hline Hospitalization- $\mathrm{N}(\%) \mathrm{N}=407$ & $56(13,8)$ & $42(13,2)$ & $14(15,7)$ & \\
\hline bDMARD suspention due to $A E-N(\%) N=407$ & $171(42)$ & $130(40,9)$ & $41(46,1)$ & \\
\hline bDMARD reintrodution after AE- $\mathrm{N}(\%) \mathrm{N}=211$ & $61(28,8)$ & $48(30)$ & $13(25,5)$ & \\
\hline
\end{tabular}

Disclosure of Interests: None declared

DOI: 10.1136/annrheumdis-2019-eular.6076

\section{SAT0144 UNDERSTANDING THE LONG-TERM OUTCOME OF RITUXIMAB - IMPLICATIONS FOR MANAGEMENT}

Leticia Garcia-Montoya, MD Yuzaiful MD Yusof, Jean Baptiste Candelier, Andrew Rawstron, Edward Vital, Paul Emery. Leeds Institute for Rheumatic and Musculoskeletal Medicine, Leeds Biomedical Research Centre, Leeds, United Kingdom

Background: In patients with rheumatoid arthritis (RA), rituximab (RTX) is often prescribed after loss of response to TNF inhibitors; however, little is known about the long-term outcome of patients receiving treatment with RTX. Previous work $[1,2]$ has shown that aiming for "complete B-cell depletion with clinical response" (CD-R) leads to an optimal management of the disease but unfortunately not all patients maintain this status. Whether CD-R can be regained with RTX retreatment remains unclear.

Objectives: To assess the outcome of RA patients treated with consecutive cycles of RTX, focusing on those who achieved complete B-cell depletion with clinical response.

Methods: A prospective 12 year observational study was conducted in RA patients who were treated with RTX in Leeds. Consecutive cycles of RTX consisting of 2 infusions of $1000 \mathrm{mg}$ were administered either on clinical relapse or a 6-monthly basis. B-cells were measured using highly sensitivity flow cytometry at 0 and 2 weeks post-RTX. Complete depletion (CD) was defined by total B-cell count $<0.0001 \times 10^{9 /} \mathrm{L}$ at week 2. Clinical response was defined by EULAR response criteria and CD-R was seen as the optimal outcome.

Results: 755 patients participated in the study of which 723 had complete data (see fig.1). The mean (range) number of RTX cycles administered was $3.8(1-14) .76 \%(549 / 723)$ of patients reached CD-R at some stage during therapy while $24 \%(174 / 723)$ never did. The latter patients had a shorter period of RTX treatment vs CD-R with an OR of 7.98 after adjusting for age, gender, prior therapy with TNF-I and concomitant DMARDs (95\% Cl 5.86-10.86); $\mathrm{p}<0.001$ (see fig.2). $84 \%$ of those who were retreated with RTX recovered CD-R (77\% of them did it in the following cycle). Half of the patients that reached CD-R maintained it in prospective cycles but $47 \%$ lost it subsequently. A third of the patients that lost either clinical response or B-cell depletion were switched to other medication without receiving further cycles. Overall, at the end of the study, $55 \%$ of all patients treated with RTX (400/723) remained in CD-R.

Conclusion: Most patients treated with RTX will achieve CD-R, but approximately half of them will lose this optimal status at some point. In patients who achieve CD-R but subsequently lose it, retreatment with
RTX appears to be an effective strategy since $80 \%$ of them will regain it and will maintain long-term treatment with therapy

\section{REFERENCES}

[1] Md Yusof, et al. EULAR 2016

[2] Garcia-Montoya, et al. EULAR 2018

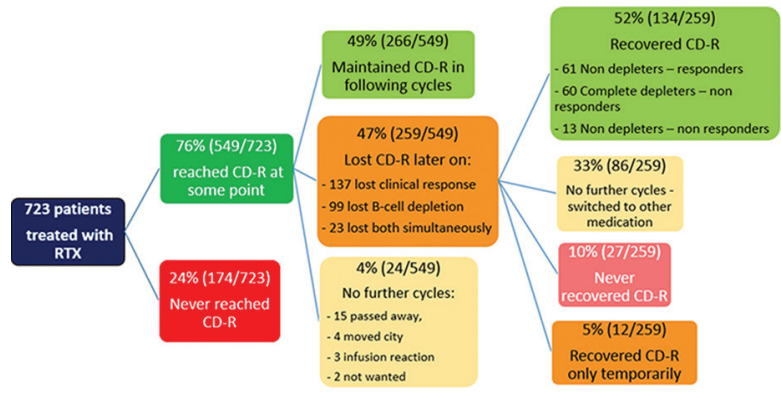

Figure 1

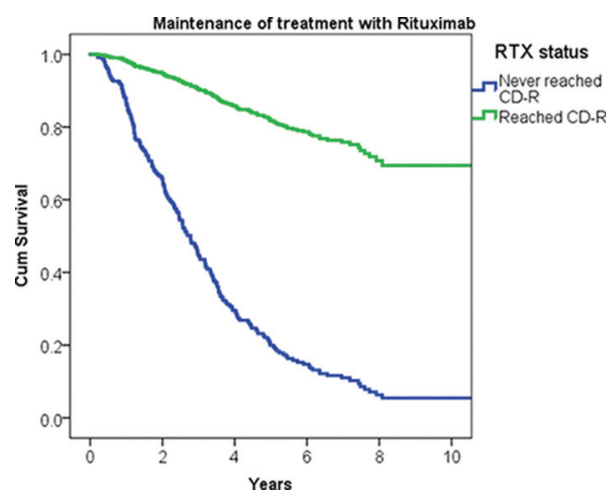

Figure 2

Acknowledgement: Shouvik Dass Maya Buch Sarah Bingham

Disclosure of Interests: Leticia Garcia-Montoya: None declared, Md Yuzaiful Md Yusof: None declared, Jean Baptiste Candelier: None declared, Andrew Rawstron: None declared, Edward Vital Grant/research support from: He has received honoraria and research grant support from Roche, GSK and AstraZeneca., Paul Emery Grant/research support from: Pfizer, MSD, AbbVie, Bristol-Myers Squibb, Roche, Consultant for: Pfizer, MSD, AbbVie, Bristol-Myers Squibb, UCB, Roche, Novartis, Gilead,Samsung, Sandoz and Lilly

DOI: 10.1136/annrheumdis-2019-eular.7601

\begin{tabular}{|l|l}
\hline SAT0145 & ON TAPERING THERAPY FOR RA PATIENTS IN \\
CLINICAL REMISSION; FLARE ON CS-DMARDS IS \\
PREDICTED BY CLINICAL PARAMETERS AND \\
ULTRASOUND, WHEREAS T-CELL ABNORMALITIES \\
ARE PREDICTIVE FOR B-DMARD TAPERING
\end{tabular}

Hanna Gul, Frederique Ponchel, Paul Emery. Leeds Institute of Rheumatic and Musculoskeletal Medicine, Rheumatology, Leeds, United Kingdom

Background: Tapering of disease-modifying therapy (DMARDs) is recommended by EULAR/ACR for rheumatoid arthritis (RA) patients who achieve sustained remission on stable therapy $(1,2)$. However, there is no guidance on how to manage this in clinical practice.

Objectives: We aimed to assess flare over 12 months in RA patients in sustained remission who were offered structured tapering of either conventional synthetic (cs) or biologic (b) DMARDs.

Methods: RA patients (ACR/EULAR 2010) prospectively attending a remission clinic were recruited when fulfilling the criteria of stable remission as defined by 3 -variable DAS28CRP $<2.6$ for $\geq 6$ months (stable therapy \& no corticosteroids). Patients were offered tapering according to a structured protocol (Figure 1). For patients receiving combination cs/bDMARDs, only the b-DMARD was tapered. Clinical, ultrasound (US) + immunological (T-cell subsets: naïve, Treg (both age-corrected) and 
inflammation related cells, IRC) data were collected. Flare over a period of 12 months was assessed using several definitions in order to evaluate their relevance for clinical outcomes. Associations with baseline characteristics were assessed using univariate statistics (Mann-Whitney-U and Chisquare). No correction for multiple testing was attempted.

Results: 98 patients (cs-DMARDs $n=66$, b-DMARDs $n=32$ ) accepted tapering and achieved at least 12 months follow-up. In the cs-DMARD group $55 \%$ were female; the median age was 64 years and median remission duration 25 months. For b-DMARDs $63 \%$ were female; the median age was 61 years and median remission duration 28 months. There was great heterogeneity in terms of flare rate according to the definitions used (Figure 2). Flare on tapering b-DMARDs was more commonly observed $(29-70 \%)$ compared to cs-DMARDs (24-52\%). Demographics were not associated with flare by any definition (except longer disease duration for cs-DMARD patients who lost Boolean remission status). Clinical (notably seropositivity) and US measures were associated with flare for cs-DMARDs. Reduced Treg and higher IRC's at baseline were associated with flare in patients tapering b-DMARDs.

Conclusion: Flare rate varied with the definition used and was more common when tapering b-DMARDs compared to cs-DMARDs. Flare was predicted in the latter patients by clinical and US (including seropositivity) findings, whereas T-cell abnormalities predicted flare in b-DMARD patients. These results will help formulate further tapering strategies.

\section{REFERENCES}

[1] Smolen JS, et al. EULAR recommendations for the management of rheumatoid arthritis with synthetic and biological disease-modifying antirheumatic drugs: 2016 update. Ann Rheum Dis. 2017.

[2] Singh JA, et al. 2015 American College of Rheumatology Guideline for the Treatment of Rheumatoid Arthritis. Arthritis \& rheumatology (Hoboken, NJ). 2016.
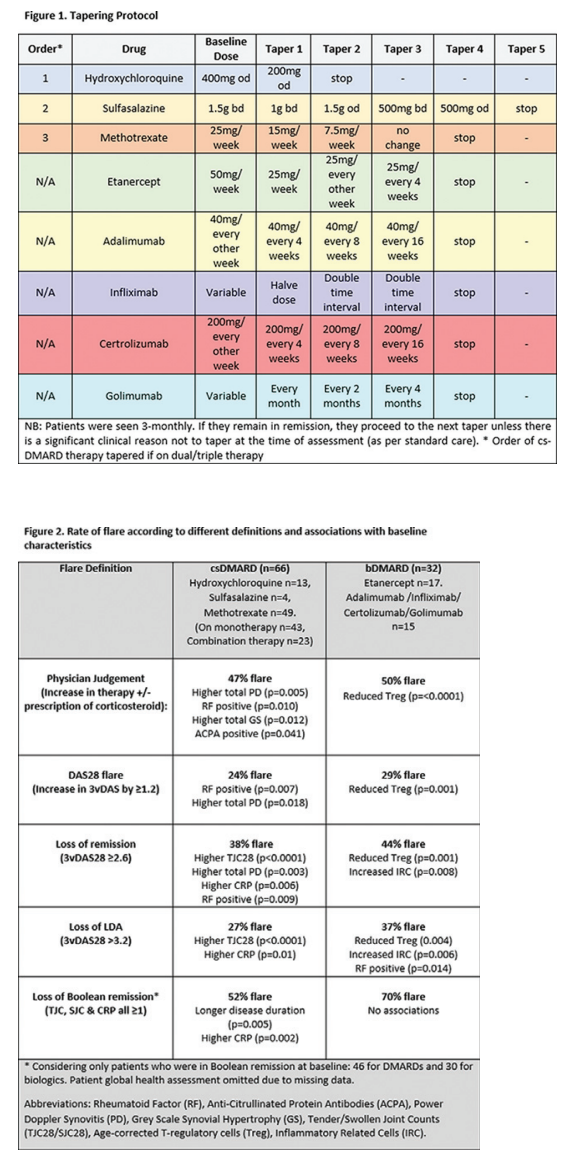

Disclosure of Interests: Hanna Gul: None declared, Frederique Ponchel: None declared, Paul Emery Grant/research support from: Pfizer, MSD, AbbVie, Bristol-Myers Squibb, Roche, Consultant for: Pfizer, MSD, AbbVie, Bristol-Myers Squibb, UCB, Roche, Novartis, Gilead,Samsung, Sandoz and Lilly

DOI: 10.1136/annrheumdis-2019-eular.6844

\section{SAT0146 COMPARING DRUG SURVIVAL FOR BIOSIMILAR SB4 ETANERCEPT IN RHEUMATOID ARTHRITIS BOTH ETANERCEPT NAÏVE AND NON-MEDICAL SWITCH PATIENTS WITH ETANERCEPT REFERENCE DRUG IN A NORWEGIAN OUT-PATIENT CLINIC. PRELIMINARY RESULTS FROM A MULTI-CENTER STUDY}

Glenn Haugeberg ${ }^{1}$, Bjørg Tilde Svanes Fevang ${ }^{2}$, Gunnstein Bakland ${ }^{3}$, Erik Rødevand ${ }^{4}$,Andreas Diamantopoulos ${ }^{5}$. ${ }^{1}$ Sørlandet Hospital Kristiansand, Rheumatology, Kristiansand, Norway, ${ }^{2}$ Haukeland hospital, Rheumatology, Bergen, Norway; ${ }^{3}$ University Hospital of North Norway HF, Rheumatology, Tromsø, Norway; ${ }^{4}$ St Olav's Hospital HF, Rheumatology, Trondheim, Norway, ${ }^{5}$ Martina Hansens Hospital, Rheumatology, Bærum, Norway

Background: In Norway encouraged by the health authorities non-medical switch from reference drug to biosimilar drug has been performed in mos patients on biologic reference drugs with biosimilar drugs available, including etanercept. There is a need for real life data understanding the effect of biosimilar drugs when these drugs are introduced in clinical practice. Objectives: To explore drug survival for biosimilar SB4 etanercept in RA patients, both etanercept naïve and non-medical switch patients, and compare with the etanercept reference drug.

Methods: Preliminary 2 years drug survival data from one center in a 5 center study in Norway exploring drug survival for etanercept reference drug and biosimilar etanercept SB4 is presented. At this outpatient clinic RA patients as part of standard clinical care has been monitored systematically since 2003. Drug survival for SB4 etanercept, both the etanercept naïve and the non-medical SB4 switch group, was compared with patients treated with the etanercept reference drug in the period 20032018. Baseline demographic, clinical and treatment data were retrieved and analyzed. Kaplan-Meier survival curves were used to explore 2 years drug survival. Survival differences between groups were tested using Breslow statistics.

Results: At the outpatient clinic the number of RA patients treated with etanercept reference drug was 356, the number of patients treated with SB4 with no previous etanercept was 36 and the patients with a nonmedical switch from reference etanercept to etanercept SB4 was 84. In the table below baseline demographics and disease measures are shown for the etanercept reference group, the non-medical SB4 switch group and the SB4 naïve to etanercept group. Data in table are presented as percentage for group variables and as mean with standard deviation (SD) for continuous variables.

\begin{tabular}{lccc}
\hline & $\begin{array}{c}\text { Etanercept reference } \\
(\mathrm{n}=356)\end{array}$ & $\begin{array}{c}\text { SB4 non-medical } \\
\text { switch }(\mathrm{n}=84)\end{array}$ & $\begin{array}{c}\text { SB4 etanercept naïve } \\
(\mathrm{n}=36)\end{array}$ \\
\hline Age, years & $63.7(15.4)$ & $62.2(11.6)$ & $58.1(15.3)$ \\
Females & $71.1 \%$ & $69.0 \%$ & $77.8 \%$ \\
Disease duration, & $12.6(10.3)$ & $18.3(11.2)$ & $8.5(8.4)$ \\
years & & & \\
Anti-CCP positive & $75.4 \%$ & $75.0 \%$ & $73.7 \%$ \\
DAS28 & $4.9(1.4)$ & $2.8(1.3)$ & $4.0(1.4)$ \\
ESR mm/hr & $29.5(21.5)$ & $17.6(13.7)$ & $29.2(26.3)$ \\
CRP mg/l & $20.3(23.1)$ & $5.0(6.5)$ & $13.7(16.7)$ \\
Pain (VAS 0-100) & $53.1(27.0)$ & $30.2(25.3)$ & $46.5(20.5)$ \\
Fatigue (VAS 0- & $53.4(30.6)$ & $34.4(33.4)$ & $44.7(27.6)$ \\
100) & & & \\
MHAQ & $0.78(0.56)$ & $0.51(0.61)$ & $0.71(0.44)$ \\
\hline
\end{tabular}

Mean $(95 \% \mathrm{Cl})$ drug survival for the non-medical SB4 switch group was1.53 (1.38-1.68) years, for the SB4 group with no previous etanercept 1.23 (0.95-1.51) years and for etanercept reference group 1.38 (1.311.46) years. A statistically significant difference $(p<0.02)$ was found between the groups except between etanercept reference group and the etanercept SB4 group without prior etanercept $(p=0.23)$. The percentage of RA patients starting with etanercept as first biologic drug was for etanercept reference $64.6 \%$ and for biosimilar etanercept SB4 $36.1 \%$.

In the figure below Kaplan-Meier drug survival curves are shown.

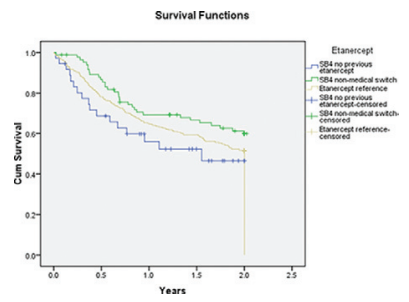

Conclusion: To the best of our knowledge this is the first data showing that drug survival of an etanercept biosimilar drug after a non-medical 